\title{
Relationship between Nutritional Status and Family History of Hypertension with Salt Taste Threshold in Adolescents in Demak Regency, Indonesia
}

\author{
Nurdiana $^{1}$, Suminah ${ }^{2}$ and Kusnandar ${ }^{3}$ \\ \{nurdiana2017@students.uns.ac.id ${ }^{1}$ \} \\ ${ }^{1,2,3}$ Universitas Sebelas Maret, Surakarta, Indonesia
}

\begin{abstract}
Demak is one of the regencies with highest prevalence of hypertension in Indonesia. The aim of the study was to evaluate the relationship between nutritional status and family history of hypertension with salt taste thresholds in adolescents in Demak Regency. The cross-sectional design was used with 100 adolescents in two high schools in the Demak Regency. Adolescent nutritional status based on BMI-for-age was obtained from anthropometric measurement. The history of family hypertension was obtained from interviews using a questionnaire. The threshold test of salt taste was carried using 6 concentration salt solution, were $4 \mathrm{mmol} / \mathrm{L}, 6 \mathrm{mmol} / \mathrm{L}, 8 \mathrm{mmol} / \mathrm{L}, 10 \mathrm{mmol} / \mathrm{L}, 12 \mathrm{mmol} / \mathrm{L}$, and $14 \mathrm{mmol} / \mathrm{L}$. Data were tested using Spearman correlation to determine the relationship between variables. The results showed that there was no significant relationship between nutritional status and family history of hypertension with salt taste threshold in adolescents ( $p=0.088$ and $p=0.485$, respectively), but the value of correlation coefficient showed a positive direction. Adolescents with a history of family hypertension showed a high threshold value of salt taste compared to adolescents who did not have a family history of hypertension. Furthermore, adolescents with overweight and obesity status indicated to have high salt taste thresholds.
\end{abstract}

Keywords: family history of hypertension, nutritional status, salt taste threshold

\section{INTRODUCTION}

Hypertension is a non-communicable disease (PTM) with a high prevalence in the world. According to the WHO report (2017) [1], in 2015 the prevalence of hypertension for age $>18$ years globally was $22.1 \%$ while in the Southeast Asian region showed higher data at $25.1 \%$. Based on Riskesdas data (2018) [2] the prevalence of hypertension in Indonesia at the age of $\geq 18$ years is $34.1 \%$.

According to Prasetyo [3], health implementation through early detection of adolescents is believed to be able to improve health status in the future. Lifestyle changes such as smoking, alcohol consumption, excessive sodium consumption, lack of physical activity and high levels of stress can lead to cardiovascular disease such as hypertension [4]. 
The high incidence of hypertension is caused by various factors including age, gender, genetics, ethnicity/race, lifestyle, medication, obesity and food intake [5], [6]. Individuals with overweight and obesity nutritional status tend to have low taste sensitivity, one of which is the sensitivity of salty taste [7]. The high threshold of salt taste is a sign that the ability to detect salt taste has decreased. The high threshold of salt taste is influenced by genetic factors and eating habits [8]. Families tend to share lifestyles especially in terms of differences in salt intake[9]. The results showed that people with higher salt intake tended to have a family history of hypertension [10].

Indonesian people have a high threshold potential for salt taste because of the habit of consuming high salt. A culture of eating that cannot be separated from salt, such as the use of MSG and flavoring in dishes that are sources of sodium is one factor in the high intake of sodium [11]. According to Baharuddin and Sharifudin[12], geographical location and culture can influence taste preferences which will have an impact on eating habits and the threshold of salt taste. Until now there has not been much research related to salt flavor threshold in adolescents in Indonesia, especially inland or non-coastal areas. Further studies are needed regarding the relationship of nutritional status and family history of hypertension with salt taste threshold in adolescents in Demak Regency, Central Java Province.

\section{METHOD}

\subsection{Respondents}

The cross-sectional design was used in the research. The population in this study were high school adolescents aged 15-17 years in non-coastal areas of Demak Regency, Central Java (N $=100$ ). The inclusion criteria in this study were adolescents who were not sick, did not smoke and lived with the family. While the exclusion criteria in this study were adolescents who did not come at the time of the study, adolescents who could not detect salty taste and young women who menstruated at the time of the study. This research was approved by the Health Research Ethics Commission of Sebelas Maret University No.52 / KEPK / 2019.

\subsection{Procedures}

Data on adolescent nutritional status were obtained from the results of anthropometric measurements of body weight and height. Classification of adolescent nutritional status based on BMI-for-age with z-score threshold according to RI Ministry of Health (2010)[13]. Family history of hypertension data was obtained through interviews using a questionnaire by asking whether or not there was a history of hypertension in the second generation (parents). Measuring the threshold of salt taste was obtained by testing 6 samples of salt solution directly by respondents with concentrations of $4 \mathrm{mmol} / \mathrm{L}, 6 \mathrm{mmol} / \mathrm{L}, 8 \mathrm{mmol} / \mathrm{L}, 10 \mathrm{mmol} / \mathrm{L}, 12$ $\mathrm{mmol} / \mathrm{L}$, and $14 \mathrm{mmol} / \mathrm{L}$.

Table 1.Criteria for classification of the study variables.

\begin{tabular}{lll}
\hline Variable & Criterion & Classification \\
\hline Nutritional Status (BMI-for- & Z-Score -3 SD to $<-2$ SD & Underweight \\
Age) & Z-Score -2 SD to 1 SD & Healthy weight \\
& Z-Score $>$ 1 SD to 2 SD & Overweight \\
& Z-Score $>2$ SD & Obesity \\
Family history of hypertension & Nothing \\
& & Father or mother \\
& & Father and mother
\end{tabular}




\subsection{Statistical analysis}

Data were analyzed using SPSS version 20. Bivariate analysis was conducted to determine the relationship between independent variables and dependent variables, namely the relationship of nutritional status and family hypertension history with the threshold of salt taste in adolescents. The statistical test used was Spearman.

\section{RESULT AND DISCUSSION}

\subsection{Characteristics of Respondents}

Table 2. General characteristics of the respondents $(n=100)$.

\begin{tabular}{ll}
\hline Variables & Value $\mathrm{n}(\%)$ \\
\hline Gender & \\
- Male & 42 \\
- Female & 58 \\
Age (years) & \\
- 15 & 6 \\
- 16 & 59 \\
- 17 & 35 \\
BMI-for-Age & \\
- Underweight & 3 \\
- Healthy weight & 77 \\
- Overweight & 19 \\
- Obesity & 1 \\
\hline
\end{tabular}

The respondents in Table 2 indicated the highest age category 16 years was $59 \%$. The biggest BMI displayed by respondents with Healthy weight category, were $77 \%$. For the obesity displayed the lower, was $1 \%$.

3.2 Comparisons of nutritional status and family history of hypertension among adolescents with salt taste threshold.

Table 3. Comparisons of nutritional status and family history of hypertension among adolescents with salt taste threshold.

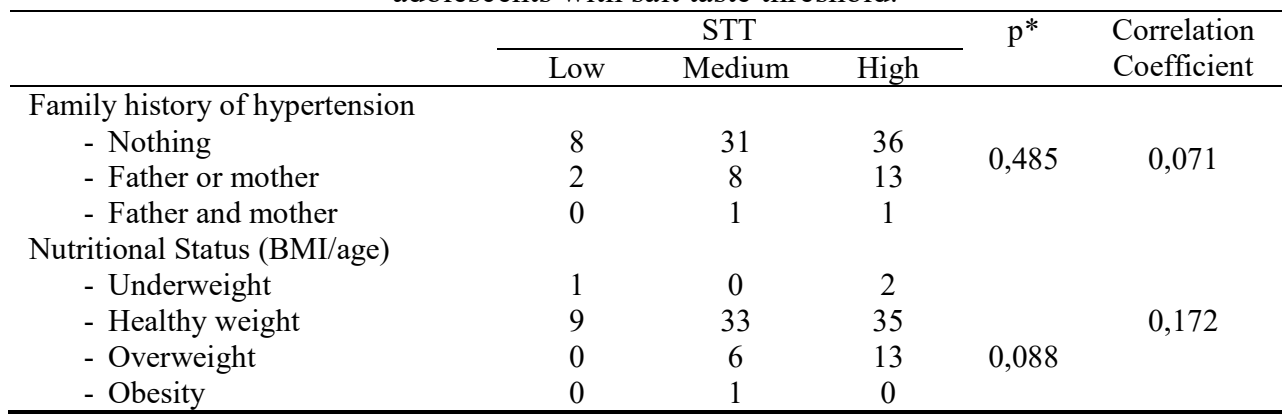


BMI, body mass index; STT, salt taste threshold.

* Spearman Correlation.

In Table 3 it can be seen that adolescents who live in non-coastal areas tend to have a high threshold of salt taste. Based on bivariate analysis, it was found that there was no significant relationship between family hypertension history and the threshold of salt taste $(p=0.486)$. However, the number of correlation coefficients shows that there is a positive relationship between family hypertension history and salt taste threshold in adolescents. Adolescents with a history of family hypertension showed a high threshold value of salt taste compared to adolescents who did not have a family history of hypertension. A history of family hypertension is strongly associated with a decrease in salt taste sensitivity [8]. According to Takeshima[9] families tend to share lifestyles, especially in terms of salt intake. The more often a person consumes food with a salty taste, the higher the threshold [14].

The results of bivariate analysis between nutritional status and salt taste threshold did not show a significant relationship $(p=0.088)$. Correlation Coefficient value of 0.172 indicates the strength and direction of the relationship between two positive variables. Adolescents with overweight and obese nutritional status showed a high threshold value of salt taste compared to adolescents with normal nutritional status. Subjects who are overweight and obese tend to have taste sensitivity disorders that have an impact on the increased desire to consume food, thus leading to excessive energy intake [15]. In obese adults it is also known to consume excess energy from foods that are classified as having salty taste and high in fat [16]. This shows that salt sensitivity can affect eating behavior and simultaneously affect one's BMI.

\section{CONCLUSION}

There was no significant relationship between nutritional status and family history of hypertension with salt taste threshold in adolescents, but the value of correlation coefficient showed a positive direction. Adolescents with a history of family hypertension showed a high threshold value of salt taste compared to adolescents who did not have a family history of hypertension. Furthermore, adolescents with overweight and obesity status indicated to have high salt taste thresholds.

\section{REFERENCE}

[1] WHO, "Global Health Observatory data repository," 2017. [Online]. Available: http://apps.who.int/gho/data/view.main.NCDBPAREGv?lang=en.

[2] Kemenkes, RI, “Riskesdas 2018,” Development, pp. 1-220, 2018.

[3] Y. B. Prasetyo, A. M. Hudha, and K. Kunci, "Pelaksanaan Program Usaha Kesehatan Sekolah Dalam Upaya Meningkatkan Derajat Kesehatan Pada Anak Usia Sekolah Dasar di Lombok Timur Implementation Health School Program to Improve Health Status for School Age at East Lombok," J. Kedokt. Yars., vol. 22, no. 2, pp. 102-113, 2014.

[4] B. N. Nkeh-Chungag, A. M. Sekokotla, C. Sewani-Rusike, A. Namugowa, and J. E. Iputo, "Prevalence of hypertension and Pre-Hypertension in 13-17 year old adolescents living in Mthatha-South Africa: A cross-sectional study," Cent. Eur. J. Public Health, vol. 23, no. 1, pp. 59-64, 2015.

[5] M. Cherfan et al., "Prevalence and risk factors of hypertension: A nationwide crosssectional study in Lebanon," J. Clin. Hypertens., no. March, 2018.

[6] Hardinsyah and I. D. N. Supariasa, Ilmu Gizi: Teori \& Aplikasi. Jakarta: EGC, 2016.

[7] F. Sartor, L. F. Donaldson, D. A. Markland, H. Loveday, M. J. Jackson, and H. P. Kubis, "Taste perception and implicit attitude toward sweet related to body mass index and soft drink supplementation," Appetite, vol. 57, no. 1, pp. 237-246, 2011. 
[8] L.H. Nikam, "Salt taste threshold and its relation to blood pressure in normotensive offspring of hypertensive parents amongst Indian adolescents," Indian J. Physiol. Pharmacol., vol. 59, no. 1, pp. 34-40, 2015.

[9] T. Takeshima, M. Okayama, R. Ae, M. Harada, and E. Kajii, "Influence of family history on the willingness of outpatients to undergo genetic testing for salt-sensitive hypertension: A cross-sectional study," BMJ Open, vol. 7, no. 7, pp. 1-7, 2017.

[10] H. Yokokawa et al., "Daily salt intake estimated by overnight urine collections indicates a high cardiovascular disease risk in Thailand," Asia Pac. J. Clin. Nutr., vol. 25, no. 1, pp. 39-45, 2016.

[11] U. Santoso, M. Gardjito, and E. Harmayani, Makanan Tradisional Indonesia Seri 2. Yogyakarta: Gajah Mada University Press, 2017.

[12] A. R. Baharuddin and M. S. Sharifudin, "The impact of geographical location on taste sensitivity and preference," Int. Food Res. J., vol. 22, no. 2, pp. 731-738, 2015.

[13] Kemenkes RI, "Keputusan Menteri Kesehatan Republik Indonesia Nomor 1995/MENKES/SK/XII/2010 tentang Standar Antropometri Penilaian Status Gizi Anak" Jakarta: Kementerian Kesehatan RI Direktorat Bina Gizi, 2010.

[14] N. K. Bobowski and J. A. Mennella, "Disruption in the Relationship between Blood Pressure and Salty Taste Thresholds among Overweight and Obese Children," J. Acad. Nutr. Diet., vol. 115, no. 8, pp. 1272-1282, 2015.

[15] B. J. Tepper, E. A. White, Y. Koelliker, C. Lanzara, P. D’Adamo, and P. Gasparini, "Genetic variation in taste sensitivity to 6-n-propylthiouracil and its relationship to taste perception and food selection," Ann. N. Y. Acad. Sci., vol. 1170, pp. 126-139, 2009.

[16] K. Keskitalo et al., "The Three-Factor Eating Questionnaire, body mass index, and responses to sweet and salty fatty foods: A twin study of genetic and environmental associations," Am. J. Clin. Nutr., vol. 88, no. 2, pp. 263-271, 2008. 